\title{
Antibacterial Efficacy of Nisin and Calcium Hydroxide with a Proton Pump Inhibitor as an Intracanal Medicament
}

\author{
${ }^{1}$ Suresh Mitthra, ${ }^{2}$ Teena Ans Abraham, ${ }^{3}$ Arunajatesan Subbiya, ${ }^{4}$ Kesavaram Padmavathy, ${ }^{5}$ Krishnan Mahalakshmi \\ ${ }^{6}$ Balasubramaniam Anuradha, ${ }^{7}$ Paramasivam Vivekanandhan
}

\section{ABSTRACT}

Aim: To evaluate the antimicrobial efficacy of nisin and calcium hydroxide with and without pantoprazole against Enterococcus faecalis in comparison with chlorhexidine $(\mathrm{CHX}) 2 \%$ solution.

Materials and methods: The antibacterial effect of the following experimental groups as intracanal medicaments (group I nisin, group II Ca(OH) 2 powder $29 \%$ conc., group III Ca(OH $)_{2}$ with pantoprazole $20 \mathrm{mg}$, group IV $\mathrm{Ca}(\mathrm{OH})_{2}$ with pantoprazole $40 \mathrm{mg}$, group $\mathrm{V} \mathrm{CHX} 2 \%$ solution, and group VI saline) was evaluated using the agar diffusion test for a time period of 24 hours. The minimum inhibitory concentration (MIC) and the minimum bactericidal concentration (MBC) against $E$. faecalis were also determined. Statistical analysis was performed using Kruskal-Wallis test and chi-square test.

Results: The agar diffusion test showed zones of inhibition for groups I, II, and V. Nisin and $\mathrm{CHX}$ groups showed the maximum zone of inhibition compared with other experimental groups. The MIC values for the experimental groups I, II, III, and V were $0.2 \mathrm{mg} / \mathrm{mL}, 0.45 \%, 0.45 \%+0.03 \mathrm{mg} / \mathrm{mL}$, and $\leq 0.01 \%$ respectively. The MBC values were tabulated.

Conclusion: The antimicrobial efficacy of nisin as an intracanal medicament was similar to $\mathrm{CHX} 2 \%$; $\mathrm{Ca}(\mathrm{OH})_{2}$ with pantoprazole was not effective against $E$. faecalis. The MIC value of nisin is $0.2 \mathrm{mg} / \mathrm{mL}$ against $E$. faecalis.

Clinical significance: Nisin, when used as an intracanal medicament, is effective in eliminating $E$. faecalis when compared with the combination of $\mathrm{Ca}(\mathrm{OH})_{2}$ with pantoprazole, a proton pump inhibitor (PPIs).

Keywords: Enterococcus faecalis, Intracanal medicament, Nisin, Pantoprazole.

How to cite this article: Mitthra $S$, Abraham TA, Subbiya A, Padmavathy K, Mahalakshmi K, Anuradha B, Vivekanandhan P. Antibacterial Efficacy of Nisin and Calcium Hydroxide with a Proton Pump Inhibitor as an Intracanal Medicament. World J Dent 2018;9(2):111-116.

1-3,6,7 Department of Conservative Dentistry and Endodontics Sree Balaji Dental College \& Hospital, Bharath Institute of Higher Education and Research, Chennai, Tamil Nadu, India

4,5 Department of Microbiology, Sree Balaji Dental College \& Hospital, Bharath Institute of Higher Education and Research Chennai, Tamil Nadu, India

Corresponding Author: Suresh Mitthra, Department of Conservative Dentistry and Endodontics, Sree Balaji Dental College \& Hospital, Bharath Institute of Higher Education and Research, Chennai, Tamil Nadu, India, Phone: +919551416503 e-mail: malu.dr2008@yahoo.com
Source of support: Nil

Conflict of interest: None

\section{INTRODUCTION}

Enterococcus faecalis is the most common facultative anaerobic bacteria isolated from both secondary and persistent root canal infections. Studies conducted by Love, ${ }^{1}$ Stuart et $a{ }^{2}{ }^{2}$ and Sirén et $\mathrm{al}^{3}$ have shown that apart from the contributing factors, such as complex root canal anatomy and ineffective chemomechanical instrumentation, E. faecalis possesses certain virulence factors (lytic enzymes, cytolysin, aggregation substance, pheromones, and lipoteichoic acid), invades and adheres to the dentinal tubules with a depth of penetration ranging from 500 to $1000 \mu \mathrm{m}$, and has the ability to survive in harsh environmental conditions due to its potential to transform into the viable but noncultivable (VBNC) state.

Calcium hydroxide, commonly used as an intracanal medicament, has an effective antibacterial action against most endodontic microflora. But $E$. faecalis is resistant to the antimicrobial activity of $\mathrm{Ca}(\mathrm{OH})_{2}$ due to its PPI action and its potential to withstand high alkalinity. The $\mathrm{pH}$ in the canal reaches neutral levels (in the presence of $E$. faecalis) on the use of $\mathrm{Ca}(\mathrm{OH})_{2}$, leading to bacterial growth and survival in the root canal. ${ }^{3}$ According to Tang et al, ${ }^{4}$ there are three major reasons for bacterial survival and growth despite the use of calcium hydroxide dressing: (1) The capacity of some bacteria to survive in dentinal tubules and ramifications, (2) $\mathrm{pH}$ in the canal reaches neutral levels after a rapid use of all the $\mathrm{Ca}(\mathrm{OH})_{2}$, and (3) the microleakage of the temporary filling. However, studies conducted by various authors have shown that $2 \% \mathrm{CHX}$ gel is effective in completely eliminating $E$. faecalis from the dentinal tubules up to a period of 15 days, attributed to its substantive antimicrobial activity. ${ }^{5,6}$

The search for an effective intracanal medicament aims to achieve superior disinfection of the root canal system, long-term clinical success of endodontic therapy, and to increase the strength and stability of the radicular dentin collagen. This led to the recent advances in the development of various materials that can be used as intracanal medicaments, such as Propolis, bioactive glass, ozonated water, corticosteroids, grape seed extract, octenidine, Nisin, ${ }^{7}$ and PPIs. 
Nisin, a chemical commonly used as a food preservative (meat and dairy products), is recently recommended for use as an intracanal medicament. Discovered in 1928, it is a naturally occurring antimicrobial cationic peptide, produced by Streptococcus lactis subspecies lactis. Chemically, it is a polycyclic antimicrobial peptide with 34 amino acid residues which includes uncommon amino acids, such as lanthionine, methyllanthionine, didehydroalanine, and didehydroaminobutyric acid. It has antimicrobial activity against a wide range of Gram-positive bacteria and their spores, even against drug-resistant E. faecalis isolates. ${ }^{8-11}$

Proton pump inhibitors are a group of drugs with the mechanism of action of pronounced and long-lasting reduction of gastric acid secretion, most commonly used for the treatment of peptic ulcer. ${ }^{12}$ Previous studies conducted have shown that the association of omeprazole with calcium hydroxide displayed selective antimicrobial activity against Endodontic microbes. ${ }^{13}$ Therefore, in this study, a more potent PPI, pantoprazole, commercially available in a tablet form 20 and $40 \mathrm{mg}$, was used. In this study, the synergistic effect of pantoprazole with $\mathrm{Ca}(\mathrm{OH})_{2}$ against E. faecalis was investigated. The PPIs not only reduce acid secretion but also increase the sensitivity to antimicrobials, maintaining the alkaline $\mathrm{pH} .{ }^{14}$ Hence, this study aimed at evaluating the antimicrobial efficacy of nisin and calcium hydroxide with and without pantoprazole against $E$. faecalis in comparison with $\mathrm{CHX} 2 \%$ solution.

\section{MATERIALS AND METHODS}

\section{Bacterial Strain used in the Study}

Enterococcus faecalis ATCC 29212 (American Type Culture Collection) was maintained in the Microbiology laboratory of our institution and was revived in Mueller Hinton Broth (MHB, HiMedia, India) and stored at $4^{\circ} \mathrm{C}$. Fresh subcultures were made on MacConkey agar plates (HiMedia, India).

The experimental groups used in the study are tabulated in Table 1.

\section{Preparation of the Stock Solutions}

Group I-Nisin: Nisin (Bimal Pharma Pvt Ltd, Mumbai, India) dissolved in sterile injectable water at a concentration of $10 \mathrm{mg} / \mathrm{mL}$.

Group II- $\mathrm{Ca}(\mathrm{OH})_{2}: \mathrm{Ca}(\mathrm{OH})_{2}$ (ProDent, Rathanagiri, India) was prepared in sterile distilled water at a concentration of $29 \%$.

Table 1: Experimental groups

\begin{tabular}{ll}
\hline Groups & Experimental groups \\
\hline I & Nisin \\
II & $\mathrm{Ca}(\mathrm{OH})_{2}$ powder $29 \%$ concentration \\
III & Pantoprazole $20 \mathrm{mg}$ with $\mathrm{Ca}(\mathrm{OH})_{2}$ powder \\
IV & Pantoprazole $40 \mathrm{mg}$ with $\mathrm{Ca}(\mathrm{OH})_{2}$ powder \\
V & $\mathrm{CHX} 2 \%$ solution (positive control) \\
VI & Saline (negative control) \\
\hline
\end{tabular}

Group III- $\mathrm{Ca}(\mathrm{OH})_{2}+$ Pantoprazole $(20 \mathrm{mg}): \mathrm{Ca}(\mathrm{OH})_{2}$ (2.9 gm) + Pantoprazole (ALKEM laboratories, India) (20 $\mathrm{mg})$ were dissolved in $10 \mathrm{~mL}$ of sterile injectable water.

Group IV-Ca(OH) 2 + Pantoprazole $(40 \mathrm{mg}): \mathrm{Ca}(\mathrm{OH})_{2}$ $(2.9 \mathrm{gm})+$ Pantoprazole $(40 \mathrm{mg})$ were dissolved in $10 \mathrm{~mL}$ of sterile injectable water.

Group $V$ - CHX 2\% solution commercially available as Asep RC (Anabond Stedman Pharma Research Ltd, Chennai) was used.

Group VI-Saline was used (Nirlife, Nirma Ltd, India).

\section{AGAR DIFFUSION ASSAY}

Agar diffusion assay was done according to Clinical Laboratories Standards Institute (CLSI) guidelines. ${ }^{15}$ Using the well diffusion susceptibility test, the antibacterial efficacy was detected by challenging bacterial isolates with antibacterial agents on the wells that were created on the surface of an agar plate seeded with a lawn culture of E. faecalis for 24 hours (Fig. 1).
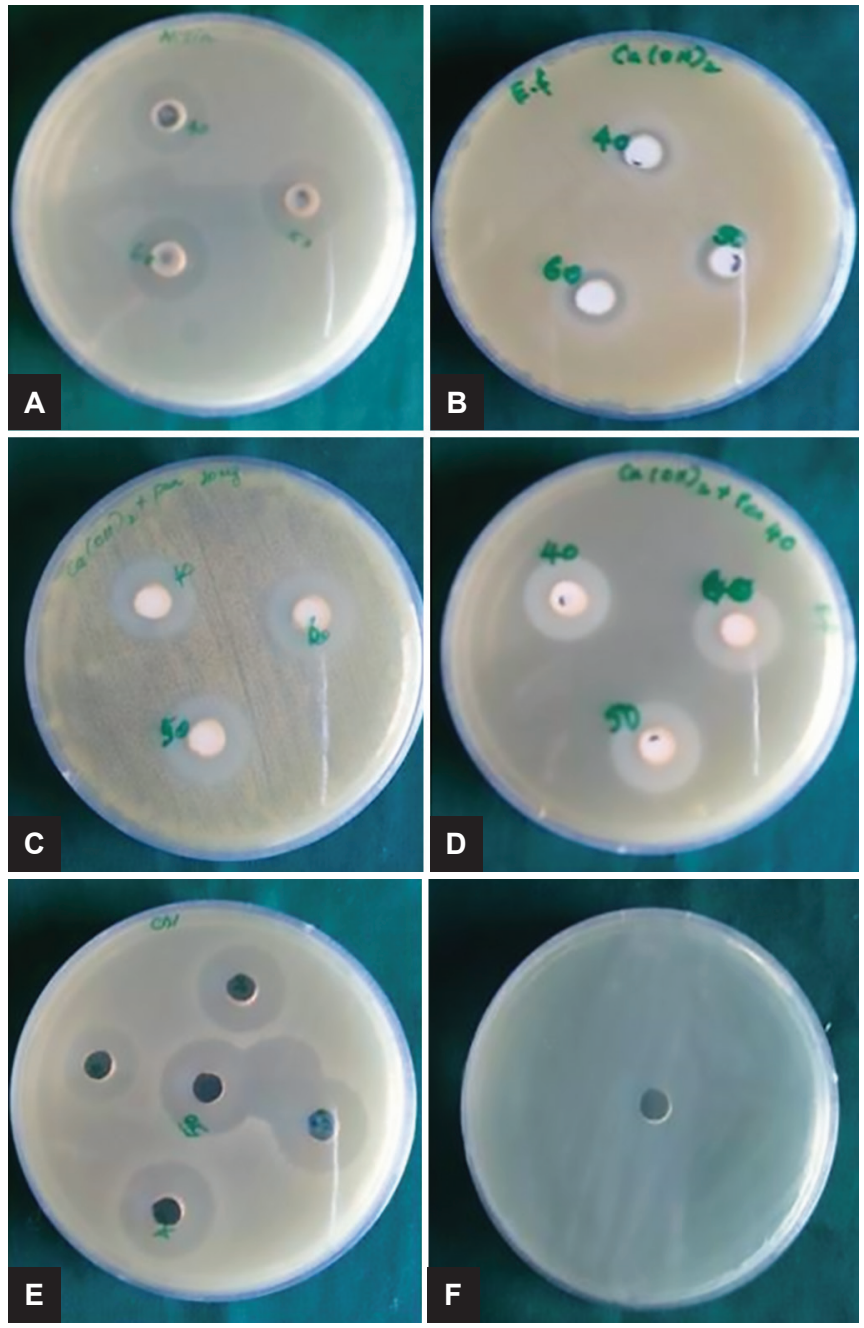

Figs 1A to $\mathbf{F}$ : Agar diffusion assay. (A) Nisin, (B) $\mathrm{Ca}(\mathrm{OH})_{2}$, (C) pantoprazole $20 \mathrm{mg}+\mathrm{Ca}(\mathrm{OH})_{2}$, (D) pantoprazole $40 \mathrm{mg}+$ $\mathrm{Ca}(\mathrm{OH})_{2},(\mathrm{E}) \mathrm{CHX} 2 \%$, (F) saline 


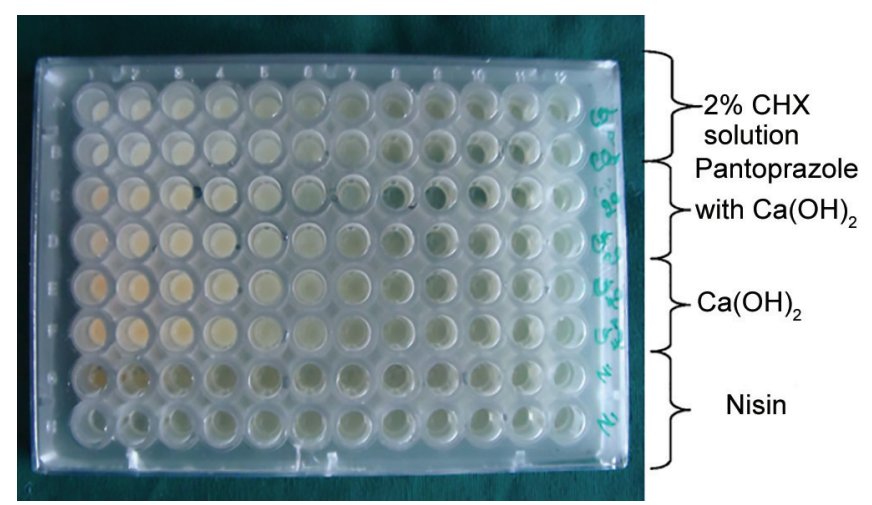

Fig. 2: Microbroth dilution assay to determine MIC

\section{Minimum Inhibitory Concentration}

Microbroth dilution assay was done to determine the MIC value of the test solutions (groups I-III \& V) as per CLSI Institute guidelines. ${ }^{15}$ The analysis was performed using doubling dilutions of the test solutions. The test solutions were double serially diluted from wells 1 to 11 of each row. The last well of each row served as the culture control (no test solution was added). The assay was performed in triplicates for all the test solutions. The MIC is the lowest concentration of the test solution that completely inhibited the growth of E. faecalis (Fig. 2).

\section{Minimum Bactericidal Concentration}

The MBC was determined by spot inoculating onto Mueller Hilton agar plates. Plates were incubated at $37^{\circ} \mathrm{C}$ overnight. The absence of growth was scored as a bactericidal activity (Fig. 3).

\section{Statistical Analysis}

Statistical analysis was done using Kruskal-Wallis Test and chi-square test. There was statistically significant difference when the probability value was $\mathrm{p}<0.05 \%$.

\section{RESULTS}

\section{Agar Well Diffusion Assay}

The antibacterial efficacy was detected by the formation of the zone of inhibition around the wells inoculated with the experimental groups. Groups I, II, and V showed inhibitory zones. The maximum diameter of $28 \mathrm{~mm}$ was obtained with $\mathrm{CHX} 2 \%$ at $60 \mu \mathrm{L}$ conc. The inhibitory zones of nisin at $40 \mu \mathrm{L}(20 \mathrm{~mm}), 50 \mu \mathrm{L}(21 \mathrm{~mm})$, and $60 \mu \mathrm{L}(21 \mathrm{~mm})$ were comparable to the positive control (Table 2).
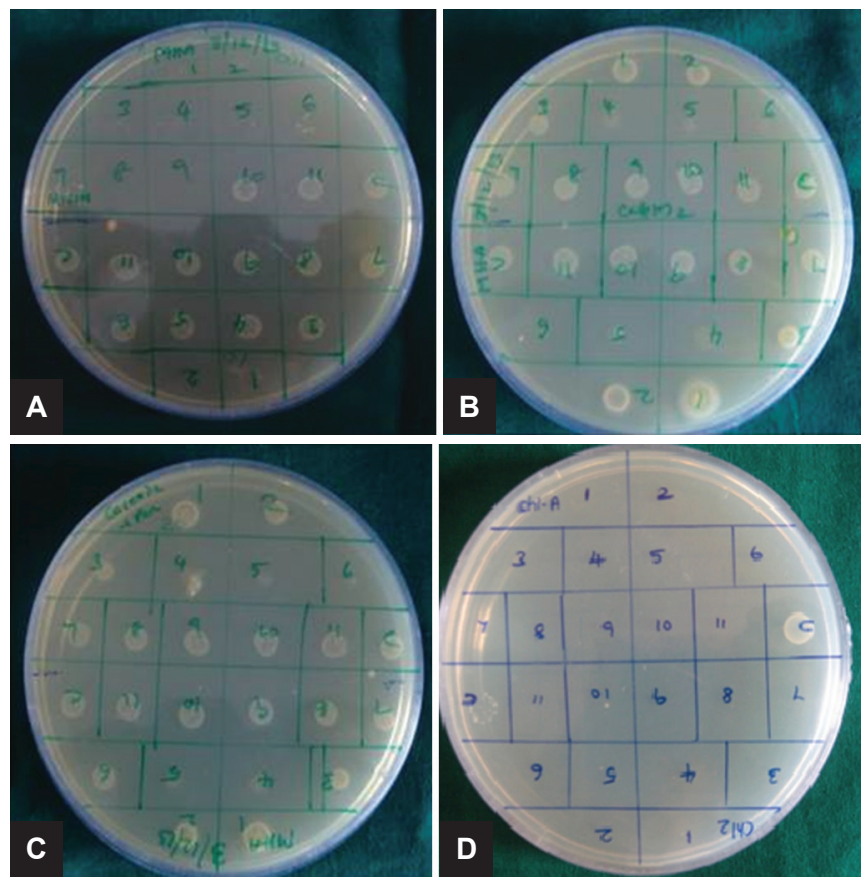

Figs $3 A$ to D: Minimum bactericidal concentration of $(A)$ Nisin, (B) $\mathrm{Ca}(\mathrm{OH})_{2},(\mathrm{C})$ pantoprazole $+\mathrm{Ca}(\mathrm{OH})_{2}$, (D) $\mathrm{CHX}$

Table 2: Agar well diffusion assay

\begin{tabular}{llll}
\hline & \multicolumn{3}{c}{$\begin{array}{c}\text { Diameter }(\mathrm{mm}) \text { of the zone } \\
\text { of inhibition }\end{array}$} \\
\cline { 2 - 4 } Test solution & $40 \mu \mathrm{L}$ & $50 \mu \mathrm{L}$ & $60 \mu \mathrm{L}$ \\
\hline Nisin $(10 \mathrm{mg} / \mathrm{mL})$ & 20 & 21 & 21 \\
$\mathrm{Ca}(\mathrm{OH})_{2}(29 \%)$ & 13 & 13 & 15 \\
$\mathrm{Ca}(\mathrm{OH})_{2}(29 \%)+$ pantoprazole & No zone & No zone & No zone \\
$(20 \mathrm{mg})$ & & & \\
$\mathrm{Ca}(\mathrm{OH})_{2}(29 \%)+$ pantoprazole & No zone & No zone & No zone \\
$(40 \mathrm{mg})$ & & & \\
$\mathrm{CHX}(2 \%)($ positive control) & 24 & 25 & 28 \\
Saline (negative control) & No zone & No zone & No zone \\
\hline
\end{tabular}

There was no statistically significant difference between nisin and CHX groups. Pantoprazole with $\mathrm{Ca}(\mathrm{OH})_{2}$ and saline groups showed no zone of inhibition. There was no statistically significant difference between groups III, IV, and VI (that expressed reduced antimicrobial efficacy) compared with the other experimental groups (Table 3 and Graph 1).

\section{Minimum Inhibitory Concentration}

The MIC values of the experimental groups against planktonic cells of E. faecalis ATCC 29212 according to this study are given in Table 4 . There was no statisti-

Table 3: Statistical analysis-agar well diffusion assay

\begin{tabular}{lllllll}
\hline & & & $\mathrm{Ca}(\mathrm{OH})_{2}(29 \%)+$ & $\mathrm{Ca}(\mathrm{OH})_{2}(29 \%)+$ & \\
Groups & Nisin $(10 \mathrm{mg} / \mathrm{mL})$ & $\mathrm{Ca}(\mathrm{OH})_{2}(29 \%)$ & pantoprazole $(20 \mathrm{mg})$ & pantoprazole $(40 \mathrm{mg})$ & $\mathrm{CHX}(2 \%)$ & Saline \\
\hline Chi-Square & 2.000 & 2.000 & 0 & 0 & 2.000 & 0 \\
Degree of freedom & 2 & 2 & 2 & 2 & 2 & 2 \\
p-value & 0.368 & 0.368 & 1.000 & 1.000 & 0.368 & 1.000 \\
\hline
\end{tabular}




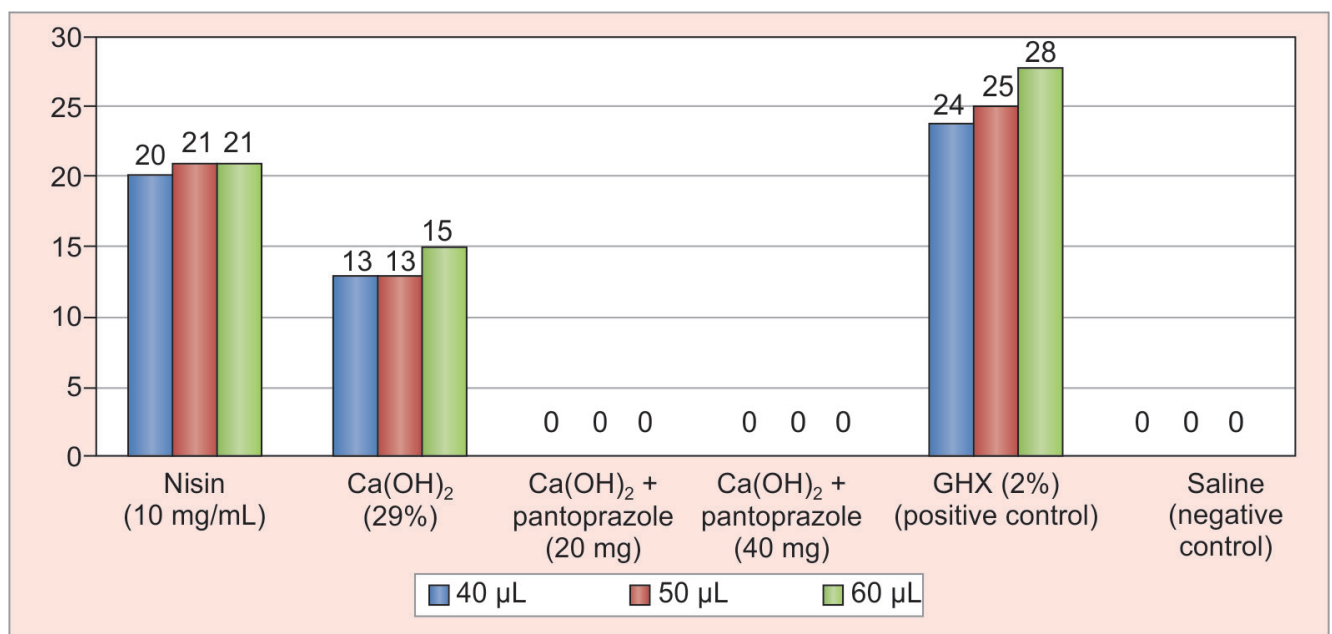

Graph 1: Agar diffusion assay

Table 4: MIC values

\begin{tabular}{llllll}
\hline Test solution & Nisin & $\mathrm{Ca}(\mathrm{OH})_{2}$ & $\mathrm{Ca}(\mathrm{OH})_{2}+$ pantoprazole & $\mathrm{CHX}(2 \%)$ & Growth control \\
\hline E. faecalis ATCC 29212 & $0.2 \mathrm{mg} / \mathrm{mL}$ & $0.45 \%$ & $0.45 \%, 0.03 \mathrm{mg} / \mathrm{mL}$ & $\leq 0.01 \%$ & $\checkmark$ \\
\hline
\end{tabular}

Table 5: Statistical analysis table for MIC values

\begin{tabular}{|c|c|}
\hline \multicolumn{2}{|c|}{ Test statistics } \\
\hline \multicolumn{2}{|c|}{$\begin{array}{l}\text { MIC of experimental groups against planktonic cells of } E . \\
\text { faecalis ATCC } 29212\end{array}$} \\
\hline Chi-square & $0.600^{\mathrm{a}}$ \\
\hline Degree of freedom & 3 \\
\hline p-value* & 0.896 \\
\hline
\end{tabular}

cally significant difference between nisin and the other experimental groups (Table 5).

\section{DISCUSSION}

The results showed that the experimental groups (I, nisin; II, calcium hydroxide; IV, CHX) exhibited antimicrobial action against E. faecalis. In the current study, nisin exhibited superior antimicrobial activity compared with $\mathrm{Ca}(\mathrm{OH})_{2}$. This is because the antimicrobial mechanism of nisin is independent of the $\mathrm{pH}$ of the surrounding tissues. This provides a means to eradicate $E$. faecalis by a method to which it has no defense mechanism. ${ }^{8}$

In the present study, the antimicrobial effect of nisin was similar to $\mathrm{CHX} 2 \%$ solution, which was similar to the result obtained in the previous study conducted by Chinni et al. ${ }^{9}$ However, Turner et $\mathrm{al}^{16}$ showed that the antimicrobial activity of nisin was similar to calcium hydroxide in eliminating E. faecalis from radicular dentin walls. Nisin has a potent antimicrobial activity against a wide range of gram-positive microorganisms. Experiments conducted by Severina et $\mathrm{al}^{10}$ proved that nisin is less toxic, odorless, colorless, tasteless, and has low drug resistance rates compared with other similar antimicrobial peptides. Nisin exhibits its antibacterial effect by the following mechanisms: According to Jack et al, ${ }_{1}^{17}$ it acts by inserting into the bacterial plasma membrane and triggering the activity of bacterial murein hydrolases, resulting in damage or degradation of the peptidoglycans and lysis of cells. Du Plessis et $\mathrm{al}^{18}$ reported that it is due to interaction with the phospholipid membrane of the target bacterial cell causing autolysis and irreparable damage to plasma membrane. Crandal et $\mathrm{al}^{19}$ showed that it disrupts the cellular mechanism, inducing leakage of small intracellular contents from the cell. ${ }^{711,16,20}$

Tong et $\mathrm{al}^{20,21}$ evaluated the combined antimicrobial efficacy of Mixture of Doxycycline, citric acid and a detergent (Tween 80) with nisin as an intracanal medicament; the results indicated that nisin (in combination with doxycycline) improves the antimicrobial action of calcium hydroxide against pathogenic bacteria. Nisin exerts its antibacterial action by forming pores in cell membranes, disrupting cell wall synthesis, and causes rapid efflux of essential cytoplasmic small molecules. The pores made by nisin facilitate the penetration of hydroxyl ions of calcium hydroxide producing bactericidal action.

The maximum diameter of $28 \mathrm{~mm}$ was observed at $60 \mu \mathrm{L}$ conc. of $2 \% \mathrm{CHX}$ solution. The MIC value for $2 \%$ CHX solution was $0.01 \%$. Chlorhexidine is bacteriostatic at lower concentrations and bactericidal at higher concentrations $(2 \%)$, and shows the property of substantivity. Various studies have shown the antimicrobial efficacy of $2 \% \mathrm{CHX}$ used as an intracanal medicament against E. faecalis. ${ }^{22,23}$

In group II, $29 \%$ concentration of $\mathrm{Ca}(\mathrm{OH})_{2}$ showed 13 to $15 \mathrm{~mm}$ zone of inhibition. The antibacterial effect 
of calcium hydroxide is related to the release and diffusion of hydroxyl radicals and the velocity of its release depends on the vehicle with which it is manipulated. The ion release is retarded with a viscous vehicle and is accelerated with an aqueous vehicle. ${ }^{22,24}$ Hence, distilled water was used as a vehicle in this study for the preparation of the stock solution of $\mathrm{Ca}(\mathrm{OH})_{2}$ with pantoprazole.

The reduced antibacterial efficacy of $\mathrm{Ca}(\mathrm{OH})_{2}$ against $E$. faecalis in this study may be due to the difference in the methodology when compared with other experimental studies. ${ }^{25,26}$ The antimicrobial activity of calcium hydroxide is attributed to its alkaline $\mathrm{pH}$. The mechanism of action includes the following: Inhibition of bacterial proliferation, alteration of bacterial cell wall, denaturation of endotoxin, and lipopolysaccharide. However, E. faecalis neutralizes the alkaline $\mathrm{pH}$ of $\mathrm{Ca}(\mathrm{OH})_{2}$ by its PPI action.

In the present study, pantoprazole was combined with $\mathrm{Ca}(\mathrm{OH})_{2}$ to enhance the antibacterial efficacy by inhibiting the proton pump mechanism and maintaining the alkaline $\mathrm{pH}$. The agar diffusion test showed no zone of inhibition for groups III (20 mg) and IV (40 mg) of pantoprazole with $\mathrm{Ca}(\mathrm{OH})_{2}$. This may be due to the interaction between pantoprazole and $\mathrm{Ca}(\mathrm{OH})_{2}$, and pantoprazole neutralized the antibacterial action of $\mathrm{Ca}(\mathrm{OH})_{2} \cdot{ }^{14}$ In previous studies by Wagner et $\mathrm{al}^{13}{ }^{13}$ the combination of omeprazole, a PPI, with $\mathrm{Ca}(\mathrm{OH})_{2}$ as an intracanal medicament showed an increased antimicrobial efficacy against E. faecalis producing superior healing of periapical lesions with an increase in reparative bone areas in male Wistar rats. Another in vivo experimental study conducted by Gandi et $\mathrm{al}^{27}$ in which $8.5 \%$ omeprazole $+5.2 \% \mathrm{NaOCl}$ were used as the final irrigant, the microbial samples collected after 28 days of inducing periapical lesions showed a superior bactericidal activity against $E$. faecalis and the healing of the periradicular lesions with a decrease in the colony-forming units in comparison with other irrigants, namely CHX and MTAD.

The drawbacks of this study include the following: The antimicrobial efficacy of the experimental groups was not tested on root canal biofilm samples; the antimicrobial efficacy of pantoprazole may be inhibited by the agglomerate formation when combined with calcium hydroxide and the reduced diffusion ability of the experimental stock solution when the agar diffusion assay was used for testing; the $\mathrm{pH}$ of the experimental groups III and IV after the combination of calcium hydroxide with 20 and $40 \mathrm{mg}$ of pantoprazole should have been evaluated before the testing the antimicrobial efficacy.

However, it remains clear that further studies are required to evaluate the chemical interaction between pantoprazole and $\mathrm{Ca}(\mathrm{OH})_{2}$ and its antibacterial efficacy against $E$. faecalis at various concentrations.

\section{CONCLUSION}

The results of the present study concluded that:

- The antimicrobial efficacy of nisin as an intracanal medicament was similar to $\mathrm{CHX} 2 \%$.

- Pantoprazole with calcium hydroxide was not effective against $E$. faecalis.

- The MIC value of nisin is $0.2 \mathrm{mg} / \mathrm{mL}$ against $E$. faecalis.

\section{CLINICAL SIGNIFICANCE}

Nisin, when used as an intracanal medicament, is effective in eliminating $E$. faecalis when compared with the combination of $\mathrm{Ca}(\mathrm{OH})_{2}$ with pantoprazole, a PPI.

\section{REFERENCES}

1. Love RM. Enterococcus faecalis - a mechanism for its role in endodontic failure. Int Endod J 2001 Jul;34(5):399-405.

2. Stuart CH, Schwartz SA, Beeson TJ, Owatz CB. Enterococcus faecalis-its role in root canal treatment failure and current concepts in retreatment. J Endod 2006 Feb;32(2):93-98.

3. Sirén EK, Haapasalo MP, Waltimo TM, Ørstavik D. In vitro antibacterial effect of calcium hydroxide combined with chlorhexidine or iodine potassium iodide on Enterococcus faecalis. Eur J Oral Sci 2004 Aug;112(4):326-331.

4. Tang G, Samaranayake LP, Yip HK. Molecular evaluation of residual endodontic microorganisms after instrumentation, irrigation and medication with either calcium hydroxide or Septomixine. Oral Dis 2004 Nov;10(6):389-397.

5. Jeasonne MJ, White RR. A comparison of $2 \%$ chlorhexidine gluconate and 5.25\% sodium hypochlorite as antimicrobial endodontic irrigants. J Endod 1994 Jun;20(6):276-278.

6. Luddin N, Ahmed HM. The antibacterial activity of sodium hypochlorite and chlorhexidine against Enterococcus faecalis: a review on agar diffusion and direct contact methods. J Conserv Dent 2013 Jan;16(1):9-16.

7. Tong Z, Ling J, Lin Z, Li X, Mu Y. The effect of MTADN on 10 Enterococcus faecalis isolates and biofilm: an in vitro study. J Endod 2013 May;39(5):674-678.

8. Hemadri M, ThakurS, Sajjan G. Nisin vs. calcium hydroxideantimicrobial efficacy on Enterococcus faecalis-an in-vitro study. Int J Contemp Dent 2011 Jun;2(3):55-61.

9. Chinni SK, Veni AB, Srinivasan MR, Rajamani I. An in vitro investigation of a newer intracanal medicament Nisin on Enterococcus faecalis in comparison with chlorhexidine and calcium hydroxide. J Int Clin Dent Res Organ 2011 Jan;3(1): 21-24.

10. Severina E, Severin A, Tomasz A. Antibacterial efficacy of nisin against multidrug-resistant Gram-positive pathogens. J Antimicrob Chemother 1998 Mar;41(3):341-347.

11. Tong Z, Zhou L, Li J, Jiang W, Ma L, Ni L. In vitro evaluation of the antibacterial activities of MTAD in combination with nisin against Enterococcus faecalis. J Endod 2011 Aug;37(8):1116-1120.

12. SHANDS. Drugs and therapy bulletin. Vol. 15(1). Gainesville (FL): Shands at the University of Florida; 2001.

13. Wagner C, Barth VC Jr, de Oliveira SD, Campos MM. Effectiveness of the proton pump inhibitor omeprazole associated with calcium hydroxide as intracanal medication: an in vivo study. J Endod 2011 Sep;37(9):1253-1257. 
14. Malathi S, Abraham TA, Padmavathy K, Mahalaxmi K, Venkatesh A, Subbiya A, Vivekanandhan P, Subbiya A, Sukumaran VG. Pantaprazole-does it enhance the antibacterial efficacy of calcium hydroxide against E. faecalis? Int J Pharm Bio Sci 2015 Apr;6(2):734-739.

15. CLSI. Performance standards for antimicrobial susceptibility testing; twenty-third informational supplement. CLSI document M100-S23. Wayne (PA): Clinical and Laboratory Standards Institute; 2013.

16. Turner SR, Love RM, Lyons KM. An in vitro investigation of the antibacterial effect of nisin in root canals and canal wall radicular dentin. Int Endod J 2004 Oct;37(10):664-671.

17. Jack FW, Tagg JR, Ray B. Bacteriocins of gram positive bacteria. Microbiol Rev 1995 Jun;59(2):171-200.

18. Du Plessis DJ, Nouwen N, Driessen AJ. The Sec translocase. Biochem Biophys Acta 2011 Mar;1808(3):851-865.

19. Crandal AD, Montville T. Nisin resistance in Listeria monocytogenes ATCC 700302 is a complex phenotype. Appl Environ Microbiol 1998 Jan;64(1):231-237.

20. Tong Z, Huang L, Ling J, Mao X, Ning Y, Deng D. Effects of intracanal irrigant MTAD combined with Nisin at subMinimum Inhibitory concentration levels on Enterococcus faecalis growth and the expression of pathogenic genes. PLoS One 2009 Mar;9(3):e90235.

21. Tong Z, Zhang Y, Ling J, Ma J, Huang L, Zhang L. An in vitro study on the effects of nisin on the antibacterial activities of 18 antibiotics against Enterococcus faecalis. PLoS One 2014 Feb;9(2):e89209.

22. Dametto FR, Ferraz CC, Gomes BP, Zaia AA, Teixeira FB, de Souza-Filho FJ. In vitro assessment of the immediate and prolonged antimicrobial action of chlorhexidine gel as an endodontic irrigant against Enterococcus faecalis. Oral Surg Oral Med Oral Pathol Oral Radiol Endod 2005 Jun;99(6):768-772.

23. Bhandari S, Shivakumar AT, Patil CR. An in vitro evaluation of antimicrobial efficacy of $2 \%$ chlorhexidine gel, propolis and calcium hydroxide against Enterococcus faecalis in human root dentin. J Clin Diagn Res 2014 Nov;8(11):ZC60-ZC63.

24. Gomes BP, Ferraz CC, Vianna ME, Rosalen PL, Zaia AA, Teixeira FB, Souza-Filho FJ. In vitro antimicrobial activity of calcium hydroxide pastes and their vehicles against selected microorganisms. Braz Dent J 2002;13(3):155-161.

25. Madhubala MM, Srinivasan N, Ahamed S. Comparative evaluation of propolis and triantibiotic mixture as an intracanal medicament against Enterococcus faecalis. J Endod 2011 Sep;37(9):1287-1289.

26. Kandaswamy D, Venkateshbabu N, Gogulnath D, Kindo AJ. Dentinal tubule disinfection with $2 \%$ chlorhexidine gel, propolis, morinda citrifolia juice, $2 \%$ povidone iodine and calcium hydroxide. Int Endod J 2010 May;43(5):419-423.

27. Gandi P, Vasireddi SR, Gurram SR, Darasani K. Evaluation of antibacterial efficacy of omeprazole with sodium hypochlorite as an endodontic irrigating solution-an in vivo study. J Int Oral Health 2013 Apr;5(2):14-20. 